\title{
Serum Triglycerides as Dignostic Marker of Acute Pancreatitis in patients with DKA
}

\author{
A.A.Amer ${ }^{1}$, A.E.Elsadek ${ }^{1}$, E.G.Behiry ${ }^{2}$ and A.S.Ahmed
}

${ }^{1}$ Pediatrics Dept., Faculty of Medicine, Benha Univ., Benha, Egypt

${ }^{2}$ Clinical and Chemical Pathology Dept., Faculty of Medicine, Benha Univ., Benha, Egypt

E-Mail: abdallladarwish@yahoo.com

\begin{abstract}
Diabetes mellitus (DM) is a complex metabolic disorder characterized by chronic hyperglycemia resulting from defects in insulin secretion, insulin action, or both. Diabetic ketoacidosis (DKA) is one of the most serious complications of diabetes. Acute pancreatitis is a potentially lethal disease with varying widely Done clinical offers What's more seriousness which extend starting with gentle and confined toward oneself on a quickly progressive sickness prompting various organ disappointment Furthermore demise. Extreme hypertriglyceridemia may be A large portion usually went with by intense pancreatitis. This study pointed with survey the serum level of triglycerides Likewise symptomatic markers to intense pancreatitis for kids with DKA. This cross sectional ponder might have been directed once patients going to Benha college Hospitals, eighty four members were selected Similarly as DKA bunches. Patients the middle of 4-10 quite some time of age for kind 1 diabetes mellitus dependent upon criteria for american diabetes affiliation. Those selected patients and their groups were 1st interviewed on report a full restorative history for their state and perform a careful clinical examination. Lab Investigations: incorporated serum triglycerides, creatinine Also ABG. DKA for AP indicated essentially higher tce The point when contrasted with DKA without AP. TG might have been altogether higher over DKA with AP The point when contrasted with DKA without AP subgroups. TG demonstrated noteworthy sure connection for tce. Applying roc bend to identify symptomatic properties of triglycerides for their unoriginality for intense pancreatitis clinched alongside DKA patients, auc for triglycerides were $0.755(\mathrm{p}<0.0001)$, suggesting fundamentally predictive qualities to identifying intense pancreatitis On DKA patients. Triglycerides camwood make symptomatic markers for suspecting intense strike for pancreatitis done kids for DKA.
\end{abstract}

Keywords: Acute pancreatitis, Diabetic ketoacidosis, Serum triglycerides.

\section{Introduction}

Diabetes mellitus (DM) is an intricate metabolic issue portrayed Eventually Tom's perusing incessant hyperglycemia coming about because of defects to insulin response secretion, insulin response action, alternately both [4].

Insufficient insulin response emission or reduced tissue reactions with insulin response in the intricate pathways from claiming hormone activity bring about insufficient insulin response movement looking into target tissues, which prompts abnormalities for carbohydrate, fat, Furthermore protein digestion system. Impeded insulin response emission or movement might exist together in the same tolerant. Dm will be habitually connected with dyslipidemia Also expanded rates from claiming glycated hemoglobin. Dyslipidemia stays generally undiagnosed Also undertreated clinched alongside high hazard populations, for example, tolerant for T1DM [7].

Diabetic ketoacidosis (DKA) is a standout amongst the The majority genuine difficulties from claiming diabetes. It may be showed by hyperglycemia (blood sugar fruit $>250 \mathrm{mg} / \mathrm{dl}$ ), metabolic acidosis (arterial ph $<7$. 3 Also serum bicarbonate $<18 \mathrm{mEq} / \mathrm{L}$ ) Also ketosis. Over DKA, those decline from claiming insulin response is answerable for expansion from claiming spare greasy liver (FFA) Also exact low thickness lipoprotein (VLDL) in the liver. On addition, diminished evacuation for VLDL starting with those plasma, bringing about hypertriglyceridemia.

Intense pancreatitis is a conceivably disappointment ailment with changing generally done clinical Characteristics Furthermore seriousness which extent from gentle What's more confined toward oneself on An quickly progressive sickness prompting different organ disappointment Also passing. The mortality ranges starting with $0 \%$ in the gentle malady with $10 \%$ to sterile Also $25 \%$ for contaminated pancreatic corruption. Determination for pancreatic proteins over serum remains the gold standard to those finding from claiming intense pancreatitis. Amylase Also lipase are both proteins discharged from those pancreas Throughout the span of the illness. The plasma levels from claiming both proteins crest inside the primary 24 hours for symptoms, yet the half life for amylase clinched alongside plasma will be shorter over that about lipase. An Investigation about every last one of distributed arrangement reveals to that lipase estimation need An marginally unrivaled affectability What's more specificity and more terrific general correctness over amylase. This distinction turns into a greater amount denoted At there is a delay in the beginning blood inspecting. In spite of those distinction in the execution from claiming these two tests will be small, it will be positive [1].

This ponder pointed on evaluate the serum level of triglycerides Similarly as symptomatic markers for intense pancreatitis Previously, patients for DKA.

\section{Subjects and methods}

This cross sectional consider might have been led with respect to patients going to Benha college Hospitals,. 2. 1. Subjects:. Eighty four members were selected as DKA bunches. Those DKA assembly included 84 T1DM patients the middle of 4-10 quite some time about age, sort 1 diabetes mellitus In light of criteria for american diabetes affiliation. [3]. 


\section{2 Methods}

Those selected kids and their groups were main interviewed will report a full restorative history for their state Furthermore perform a careful clinical examination. Throughout those examination, those kids' weights Furthermore statures were measured, and their BMI might have been ascertained Also ordered as stated by the WHO arrangement list [14].

Sampling:. Blood sample:. Six ml venous blood example might have been acquired starting with every liable after 8 hours fasting.

The test might have been separated under 2 parts; $(2$ $\mathrm{ml}$ ) were place clinched alongside a sterile vacutainer tube holding di-potassium-EDTA to $\mathrm{cbc}$ and the remaining might have been cleared out should cluster a hour then centrifuged with separate serum for biochemical tests (glucose, renal functions, triglycerides).

Research center Investigations: -. 1- cbc. 2- blood glucose: glucose oxidase procedure Toward (Biosystems kits, part no. 11144). 3- serum triglycerides: utilizing triglycerides BioSystems reagent unit furnished by
Biosystems, encountered with urban decay because of deindustrialization, innovation developed, government lodgin. An. Expense pull swelling Brava 30. 08030 barcelona (SPAIN). 4- urea \&Creatinine: might have been completed utilizing jewel symptomatic reagent unit given Eventually Tom's perusing Diamond, Hannover, Germany. 5- ABG Also serum electrolytes.

\section{Results}

In our study that includes 84 children with DKA with type 1 diabetes, admitted to the pediatric intensive care units of Benha University Hospitals.

Table (1) Demographic data distribution of the study group.

\begin{tabular}{lccc}
\hline Demographic Data & & No. & \% \\
\hline Sex & Male & 43 & 51.19 \\
& Female & 41 & 48.81 \\
Onset of diabetes & New & 68 & $80.95 \%$ \\
& Known & 16 & $19.05 \%$ \\
\hline
\end{tabular}

Table (2) Metabolic and biochemical study parameters.

\begin{tabular}{llll}
\hline & Range & Mean \pm SD & Median (IQR) \\
Wt(kg) & $13-45$ & $23.00 \pm 7.21$ & $24.5(16.5)$ \\
Wt. z-score & $-3.08-2.33$ & $-0.39 \pm 1.06$ & $-0.24(1.27)$ \\
RBG ( mg/dl) & $249-1170$ & $490.86 \pm 278.74$ & $419.5(178)$ \\
pH & $6.9-7.34$ & $7.16 \pm 0.12$ & $7.1(0.24)$ \\
HCo3( mEq/l) & $1.9-14$ & $8.51 \pm 3.01$ & $7.55(4.25)$ \\
GCS & $12-15$ & $14.52 \pm 0.86$ & $15(1.25)$ \\
TG1 (mg/dl) & $75.8-10500$ & $393.53 \pm 1126.30$ & $237.75(128.85)$ \\
TG2 (mg/d) & $65.8-1850$ & $160.96 \pm 197.17$ & $115.5(133.93)$ \\
Initial insulin TDD & $0.66-1.87$ & $1.10 \pm 0.27$ & $1.1(0.5075)$ \\
TDD of insulin after 3 mo & $0.66-1.8$ & $1.18 \pm 0.26$ & $1.185(0.315)$ \\
\hline
\end{tabular}

Table (3) Prevalence of hypertriglyceridemia at onset (TG1) and at 48 hrs (TG2) of DKA.

\begin{tabular}{|c|c|c|c|c|c|c|}
\hline & \multicolumn{2}{|l|}{ TG1 } & \multicolumn{2}{|c|}{ TG2 } & \multicolumn{2}{|c|}{ Chi-square } \\
\hline & No. & $\%$ & No. & $\%$ & $\mathbf{x 2}$ & p-value \\
\hline Normal (<150 mg/dl) & 10 & 11.9 & 51 & 60.71 & 41.183 & $<0.001$ (HS) \\
\hline High $\quad(>150 \mathrm{mg} / \mathrm{dl})$ & 74 & 88.1 & 33 & 39.29 & & \\
\hline
\end{tabular}

Table (4) Difference in median triglycerides level (initial and at $48 \mathrm{hrs}$ ) in the study.

\begin{tabular}{lllllll}
\hline & \multicolumn{2}{c}{ TG1 } & \multicolumn{2}{c}{ TG2 } & \multicolumn{2}{c}{ Chi-square } \\
\cline { 2 - 7 } & No. & \% & No. & \% & x2 & p-value \\
\hline Normal (<150 $\mathbf{~ m g / d l ) ~}$ & 10 & 11.9 & 51 & 60.71 & 41.183 & $<0.001(\mathrm{HS})$ \\
High (>150mg/dl) & 74 & 88.1 & 33 & 39.29 & & \\
\hline
\end{tabular}

Table (5) Comparison between new and known according to all parameters.

\begin{tabular}{lcccc}
\hline & \multicolumn{2}{c}{ Onset } & \multicolumn{2}{c}{ t-test } \\
\cline { 2 - 5 } & New & Known & t & p-value \\
\hline Sex & $33(48.5 \%)$ & $10(62.5 \%)$ & 1.012 & 0.314 \\
Male & $35(51.5 \%)$ & $6(37.5 \%)$ & & \\
Female & $6.860 \pm 2.570$ & $8.125 \pm 2.831$ & -1.738 & 0.086 \\
Age (y) & $508.750 \pm 298.302$ & $383.500 \pm 65.761$ & 0.573 & 0.577 \\
RBS ( mg/dl) & & & &
\end{tabular}


Table (5) Continue

\begin{tabular}{lcccc}
\hline $\mathbf{p H}$ & $7.160 \pm 0.109$ & $7.147 \pm 0.142$ & 0.413 & 0.681 \\
HCo3 $(\mathbf{m E q} / \mathbf{L})$ & $8.238 \pm 3.083$ & $9.656 \pm 2.453$ & -1.714 & 0.090 \\
GCS & $14.500 \pm 0.889$ & $14.625 \pm 0.719$ & -0.523 & 0.603 \\
TG1 (mg/dl) & $417.103 \pm 1250.529$ & $293.363 \pm 145.067$ & 0.393 & 0.695 \\
TG2 $(\mathbf{m g} / \mathbf{d l})$ & $162.938 \pm 214.997$ & $146.925 \pm 79.823$ & 0.292 & 0.771 \\
TDD & $1.177 \pm 0.262$ & $1.204 \pm 0.243$ & -0.382 & 0.703 \\
TG mean & $255.209 \pm 1041.397$ & $146.438 \pm 124.669$ & 2.415 & 0.049 \\
Difference (mg/dl) & & & & \\
\hline
\end{tabular}

Table (6) Correlation between (total hospital stay \&ICU stay) and TG1.

\begin{tabular}{lcc}
\hline & \multicolumn{2}{c}{ TG1 } \\
\cline { 2 - 3 } \multicolumn{1}{c}{$\backslash$} & r & p-value \\
\hline Total Hospital stay & 0.528 & $<0.001$ \\
ICU stay & 0.370 & $<0.001$ \\
\hline
\end{tabular}

When duration of hospital stay was studied in relation to other parameters, a significant correlation ( $\mathrm{p}<$ 0.001 ) was found between onset of diabetes and duration of total hospital stay. However, ICU stay was not related to onset of diabetes.

\section{Discussion}

We found that to DKA patients who formed intense pancreatitis, triglyceride level might have been raised. Clinched alongside our cohort, 74 patients (88. 1\%) needed hyper-triglyceridemia toward onset from claiming DKA extending starting with 75. 8-10500 $\mathrm{mg} / \mathrm{dl}$ with noteworthy change for TG then afterward 48 hrs of DKA management $(\mathrm{p}<0.001)$. Our comes about were comparable with [8] who contemplated 13 patients with DKA (15-60 yrs) What's more found that preceding insulin response treatment, plasma TG levels went from $63-2800 \mathrm{mg} / \mathrm{dl}$ What's more that 12 patients out for 13 showed sensational declines On plasma TG levels Eventually Tom's perusing those 24th hr from claiming insulin response treatment.

Similarly, [17]measured plasma TG Also cholesterol focuses Previously, 50 scenes clinched alongside 46 Grown-ups hospitalized around a metropolitan healing center medicinal administration Also accounted that 32 patients (64\%) needed triglyceride levels over those 95th percentile (adjusted for agdistis Also sex), and 18 patients $(36 \%)$ needed cholesterol levels over those 95th percentile. Extreme hypertriglyceridemia (levels over 5. $65 \mathrm{mmol} / \mathrm{L}$ ) might have been discovered On 14 patients (28\%) and that medicine of the ketoacidosis might have been connected with An fast diminish for plasma lipid levels. [17] reasoned that 12 of the 15 patients for DKA What's more hypertriglyceridemia didn't need an underlying hereditary hyperlipidemia helping should their unique extreme hypertriglyceridemia Throughout DKA scene.

However, [5] analysed those lipoprotein lipase coding gene succession Previously, An 10-year-old young lady for new-onset T1D, ketoacidosis Also extreme hypertriglyceridaemia $(\mathrm{TG}>112.9 \mathrm{mmol} / \mathrm{l})$
What's more uncovered that those tolerant might have been a intensify heterozygote for two mutations, D9N in exon 2 What's more S447X done exon 9. In spite of the fact that these two mutations as a rule didn't Impressively disable lipolytic catalyst activity, the blending for both in that tolerant might have assumed An part in the improvemen from claiming extreme hypertriglyceridaemia.

\section{Conclusion}

Triglycerides can be diagnostic markers for suspecting acute attacks of pancreatitis in children with DKA.

\section{References}

[1] R.Alemzadeh, O.Ali, Type 1 diabetes mellitus (immune mediated). Nelson textbook of pediatrics ,Vol.19, PP. 1969-1990, 2011.

[2] T.A. Aly, A. Ide, M.M. Jahromi, J.M. Barker, M.S. Fernando, S. R. Babu , K.J. Barriga , Extreme genetic risk for type 1A diabetes. Proceedings of the National Academy of Sciences,Vol.103(38),PP. 14074-14079,2006.

[3] American Diabetes Association, Diagnosis and classification of diabetes mellitus. Diabetes Care , Vol. 37 (1), PP. 81-90, 2015.

[4] American Diabetes Association , Children and Adolescents. Diabetes Care, Vol. 39(1), PP. 86-93, 2016.

[5] American Diabetes Association. Standards of medical care in diabetes Diabetes Care, Vol.39(1), PP.1-106, 2016.

[6] E. E. Argueta, K. M. Nugent, Acute pancreatitis in a patient with diabetic ketoacidosis and normal lipase levels. ICU Director,Vol. 4(4), PP. 166-169, 2013.

[7] J. H.Bae, S. H.Baek, H. S.Choi, K. R.Cho, H. L.Lee, O. Y.Lee, C. S. Kee, Acute pancreatitis due to hypertriglyceridemia: report of 2 cases. The Korean J.,gastroenterology $=$ Taehan Sohwagi Hakhoe chi,Vol. 46(6), PP. 475-480, 2005.

[8] H.J. Bangstad, T. Danne, L. Deeb, P. Jarosz-Chobot, T. Urakami, R. Hanas, Insulin treatment in children and adolescents with diabetes. Pediatric diabetes ,Vol.10(12), PP. 82-99, 2009.

[9] J.C. Barrett, D.G. Clayton, P .Concannon, B. Akolkar, J.D. Cooper, H.A. Erlich , V. Plagnol, Genome-wide association study and metaanalysis find that over 40 loci affect risk of type 1 diabetes. Nature genetics, Vol. 41(6), PP. 703707, 2009. 
[10]F. Cardella , The DKA. Italian J., pediatrics, Vol.40(1), PP.1, 2014.

[11]A.P. Carlotti, S .George-Hyslop, A.M. Guerguerian, D. Bohn, K.S. Kamel,

[12]M.N. Chatterjee, R .Shinde , Text book of medical laboratory technology. Metabolism of carbohydrates. 6th edition. Delhi-India: Jaypee Brothers Medical publisher, Vol. 2005, PP.266-330, 2010.

[13] G.M. Dallinga-Thie, R. Franssen, H.L. Mooij, M.E .Visser, H.C. Hassing, F. Peelman, M. Nieuwdorp , The metabolism of triglyceride-rich lipoproteins revisited: new players, new insight. Atherosclerosis , Vol. 211(1), PP.1-8, 2010.

[14] T. Danne, J .Aman, E. Schober, D. Deiss, J.L. Jacobsen, H.H. Friberg, L.H. Jensen, A comparison of postprandial and preprandial administration of insulin aspart in children and adolescents with type 1 diabetes. Diabetes Care, Vol. 26(8), PP. 23592364, 2003.

[15] M.S. Elisaf, A.A. Tsatsoulis, K.P. Katopodis, K.C. Siamopoulos, Acid-base and electrolyte disturbances in patients with diabetic ketoacidosis. Diabetes Res Clin Pract, Vol.34, PP.23-27, 1996.

[16]P.Fossati, L.Prencipe, Serum triglycerides determined colorimetrically with an enzyme that produces hydrogen peroxide. Clinical chemistry,Vol. 28(10), PP. 2077-2080, 2009.
[17]M. Fulop, H.A.Eder, Plasma triglycerides and cholesterol in diabetic ketosis. Arch Intern Med. Sep, Vol. 149(9), PP.1997-2002.

[18]M.L. Halperin , Occult risk factor for the development of cerebral edema in children with diabetic ketoacidosis: possible role for stomach emptying. Pediatric diabetes, Vol.10(8), PP.522533, 2009.

[19] G. C.iannini, A.Mohn, F.Chiarelli, C. J. H. Kelnar, Macrovascular angiopathy in children and adolescents with T1DM.Diabetes/Metabolism Research and Reviews, Vol. 27(5), PP. 436-460, 2011.

[20]T.Kearney, C.Dang, Diabetic and endocrine emergencies. Postgraduate medical J., Vol. 83(976),PP. 79-86,2010.

[21] H. E.Larsson, K.Vehik, R.Bell, D.Dabelea, L.Dolan, C.Pihoker, R.Holl, Reduced prevalence of diabetic ketoacidosis at diagnosis of T1DMin young children participating in longitudinal follow-up.Diabetes Care, Vol. 34(11), PP. 2347-2352, 2011.

[22] S.W. Masram, M.V. Bimanpalli, S. Ghangle , Study of Lipid Profile and Glycated Hemoglobin in Diabetes Mellitus. Ind Med Gaz, Vol. 7, PP.257265, 2012.

[23]Pediatric Diabetic keto acidosis. BSPED Recommended DKA Guidelines ,2015. 